Article (refereed) - postprint

Kay, A.L.; Jones, R.G.. 2012 Comparison of the use of alternative UKCP09 products for modelling the impacts of climate change on flood frequency. Climatic Change, 114 (2). 211-230. 10.1007/s10584-011-0395-Z

(c) Springer Science+Business Media B.V. 2012

This version available http://nora.nerc.ac.uk/14539/

NERC has developed NORA to enable users to access research outputs wholly or partially funded by NERC. Copyright and other rights for material on this site are retained by the rights owners. Users should read the terms and conditions of use of this material at http://nora.nerc.ac.uk/policies.html\#access

This document is the author's final manuscript version of the journal article, incorporating any revisions agreed during the peer review process. Some differences between this and the publisher's version remain. You are advised to consult the publisher's version if you wish to cite from this article.

The final publication is available at link.springer.com 


\title{
Comparison of the use of alternative UKCP09 products for modelling the impacts of climate change on flood frequency
}

\author{
Kay $^{1}$, A.L. and Jones ${ }^{2}$, R.G. \\ ${ }^{1}$ Centre for Ecology and Hydrology, Maclean Building, Crowmarsh Gifford, \\ Wallingford, Oxfordshire, OX10 8BB, UK \\ ${ }^{2}$ Met Office Hadley Centre for Climate Prediction and Research, Fitzroy Road, \\ Exeter, EX1 3PB, UK.
}

Correspondence to: A.L. Kay (alkay@ceh.ac.uk, Tel: 01491 838800, Fax: 01491 692424)

\begin{abstract}
Climate change could have significant impacts on hydrology. This paper uses UK Climate Projections 09 (UKCP09) products to assess the impacts on flood frequency in Britain. The main UKCP09 product comprises conditional probabilistic information on changes in a number of climate variables on a $25 \times 25 \mathrm{~km}$ grid across the UK (the Sampled Data change factors). A second product is a Weather Generator which produces time-series of current weather variables and future weather variables based on the Sampled Data and consistent with the change factors. A third product comprises time-series from a Regional Climate Model (RCM) ensemble which were used to downscale Global Climate Models (GCMs) on which the projections are based and whose outputs were used in the production of the Sampled Data.
\end{abstract}

This paper compares the use of Sampled Data change factors, Weather Generator time-series, RCM-derived change factors and RCM time-series. Each is used to provide hydrological model inputs for nine catchments, to assess impacts for the 2080s (A1B emissions). The results show relatively good agreement between methods for most catchments, with the four median values for a catchment generally being within $10 \%$ of each other. There are also some clear differences, with the use of time-series generally leading to a greater uncertainty range than the use of change factors because the latter do not allow for the effects of, or changes in, natural variability. Also, the use of Weather Generator time-series leads to much greater impacts than the other methods for one catchment. The results suggest that climate impact studies should not necessarily rely on the application of just one UKCP09 product, as each has different strengths and weaknesses.

\section{Keywords}

Climate change; probabilistic climate projections; hydrological impacts; flood frequency; uncertainty.

\section{Introduction}

Anthropogenic climate change is already having significant impacts on the global hydrological cycle (IPCC 2007) and this is now being demonstrated even at the national level for the UK (Pall et al. 2011, Kay et al. 2011a). Of particular concern are potential changes in the frequency of floods and droughts. Hydrological models are often used to assess such changes, driven by timeseries considered to represent plausible future climates. For instance, Bell et al. (2009) used a grid-based hydrological model for the UK driven by time-series of precipitation and potential evaporation data derived from a $25 \mathrm{~km}$ resolution version of the HadRM3H Regional Climate Model (Jenkins et al. 2003). Their results suggested increases in flood frequency across much of the country by the 2080s, although with varying magnitude in different locations. Kay et al. (2006a) also used HadRM3H time-series data, to drive a lumped hydrological 
model for 15 individual catchments across Britain, and similarly found that the impact on flood frequency varied by catchment. Graham et al. (2007) used data from the EU PRUDENCE project (http://prudence.dmi.dk) for a variety of Global and Regional Climate Models (GCMs and RCMs). For the 2080s they found decreases in summer flows of up to $-42 \%$, in the Rhine basin, and increases in winter flows of up to $54 \%$, in the Baltic basin, suggesting possible increased problems with both droughts and floods in these basins. Dettinger et al. (2004) used downscaled GCM data for 1900-2099 to drive a hydrological model for three catchments in California. They found, by 2100 , earlier snowmelt, an increased frequency of winter flooding and reduced summer flows.

Much effort has been put into developing projections of future climate via GCMs and nested RCMs, but the cascade of uncertainty (e.g. Kay et al. 2009b, Prudhomme and Davies 2009, Wilby and Harris 2006) makes it difficult to assess the likelihood of the changes projected by any one run of one model combination. Furthermore, the complexity of such models generally makes the production of very large ensembles infeasible, particularly with fully coupled atmosphere-ocean GCMs and nested RCMs. Relatively small 'ensembles of opportunity' (e.g. from PRUDENCE) may give misleading impressions of the likely range of climate change impacts since they are not designed to sample the full range of model uncertainty (Kendon et al. 2010). The climateprediction.net project has produced very large climate model ensembles (e.g. Frame et al. 2009) by perturbing parameters in a GCM across a range of values judged plausible by experts on the GCM's representation of the climate system components (Murphy et al. 2004). These were then run on distributed computing power using personal computers, but with relatively limited information available from each ensemble member since the computers do not have the bandwidth to return large data volumes. However, New et al. (2007) used information from climateprediction.net (in the form of seasonal changes to precipitation and potential evaporation) to model changes in the median flow of the Thames at Teddington. They discuss how such a probabilistic approach can provide more informative results, but that the details are conditional on the approach.

Recently the Met Office Hadley Centre has developed a new technique to use statistical emulators (Rougier 2008) with a relatively large GCM ensemble (a 280-member perturbed-physics ensemble, or PPE) to emulate the behaviour of ensemble members using sets of untried parameters. Thus a larger emulated ensemble $\left(10^{6}\right.$ members) was generated and its members weighted according to performance compared to recent observations. This larger ensemble was then used as the basis for the UK Climate Projections 2009 (UKCP09), following the incorporation of information from several other modelling and statistical processing steps (Murphy et al. 2009). These steps included:

- modifying the ensemble according to predictions from GCMs with (structurally) different representations of the climate system;

- adding information about transient climate change based on a 17member subset of the original 280-member GCM PPE ensemble, modified to incorporate a full dynamic ocean model;

- adding detail at a finer spatial resolution based on downscaling an 11member subset of the latter 17-member GCM PPE ensemble using a $25 \mathrm{~km}$ European RCM version of the parent GCM. 
The resulting UKCP09 projections (http://ukclimateprojections.defra.gov.uk/) provide a probabilistic representation (conditional on the methodology outlined above) of (monthly, seasonal or annual) changes in a number of climate variables, averaged over seven over-lapping 30-year time-slices. The main UKCP09 product is this set of Sampled Data (as described in Murphy et al. 2009, Section 4). A weather generator is also provided (Jones et al. 2009), to enable production of daily (or hourly) time-series over defined areas based on the Sampled Data. Time-series data from the 11-member RCM PPE are also available (Murphy et al. 2009, Section 5).

In this paper, all three of the above UKCP09 products are applied; Sampled Data, Weather Generator data and RCM ensemble data. Each product is used to provide inputs for hydrological modelling, for nine catchments spread across Britain. The resulting modelled flows are then analysed in terms of flood peaks, comparing the impacts on flood frequency suggested by the application of the alternative products (for the 2080s time-slice under the A1B SRES emissions scenario, IPCC 2000). Section 2 describes the hydrological modelling, the catchments modelled, and the way in which each UKCP09 product has been applied. Section 3 presents the results, which are discussed in Section 4.

\section{Methodology}

\subsection{Hydrological modelling}

The hydrological model applied is the Probability Distributed Model (PDM; Moore 1985, 2007), a lumped, conceptual rainfall-runoff model widely applied in the UK which forms part of the River Flow Forecasting System (Moore et al. 2005). A simplified version is used here, to allow automatic calibration via Monte Carlo sampling of the parameter space of the PDM. This version has six catchment-specific parameters, three of which require calibration. A fourth is set using soils data and the remaining two are set according to catchment location. This version of the PDM, and its automatic sequential calibration method, are refinements of those described by Kay et al. (2007).

The PDM is used along with a simple temperature-dependent snowmelt module (Bell and Moore 1999), which essentially delays the input of water if temperatures are low. This model combination, when run at a daily time-step, requires daily time-series of catchment-average precipitation and potential evaporation (PE), along with a point time-series of mean daily temperature, the altitude to which the temperature relates, and information on the area of the catchment within different elevation zones (taken from a digital terrain model).

The model combination was calibrated for 120 catchments in Britain (76 at a daily time-step) as part of Defra Flood and Coastal Erosion Risk Management (FCERM) project FD2020 'Regionalised impacts of climate change on flood flows' (Reynard et al. 2009). See Crooks et al. (2009) for more detail on calibration. Briefly, for each catchment modelled at the daily time-step: daily gauged flow data were available from the UK National River Flow Archive; daily catchment-average rainfall data were estimated from gauged rainfall data from the UK National Water Archive; daily catchment-average PE data were derived from 40x40km monthly gridded Met Office Rainfall and Evaporation Calculation System data (MORECS, Thompson et al. 1982), divided equally over each day of the month; daily mean temperature time-series data were taken from the 
$5 \times 5 \mathrm{~km}$ gridded observed temperature dataset produced for UKCP09 (see Annex 1 of Jenkins et al. 2007). Calibration is a two-pass sequential process, using Monte Carlo sampling. For the first pass, each parameter is calibrated in turn following sampling of the parameter space of the so-far un-calibrated parameters. In the second pass, each parameter is re-calibrated in turn while the other parameters are held at their last calibrated values, thus allowing parameter re-adjustment.

\subsection{Catchments and flood frequency analysis}

Nine catchments are used here, details of which are given in Table 1 and their locations are shown in Figure 1. These catchments were used for the uncertainty analysis in project FD2020 (Kay et al. 2009a) where they were chosen to be representative of the range of sensitivity of catchments to changed rainfall inputs, using the sensitivity framework of Prudhomme et al. (2010).

For each catchment, simulated river flows are used to produce flood frequency curves, using the peaks-over-threshold method (Naden 1992). The impacts of climate change on daily mean peak flows are then calculated by looking at the difference between flood frequency curves simulated for current and future periods. The analysis is done for peak flows at two return periods: 2-years and 20-years. It is these impacts which are presented for each of the nine catchments, using each of the UKCP09 products and methods of application described in the next section.

\subsection{Application of UKCP09 products}

The UKCP09 products and variables applied are:

1. Sampled Data change factors: 10,000 monthly 'change factors' for precipitation and temperature;

2. Weather Generator time-series of daily precipitation, minimum and maximum temperature and PE (from version 1 of the Weather Generator);

3. RCM ensemble data for daily precipitation, mean temperature and PE, from the 11-member ensemble.

Although UKCP09 generally provides information for seven over-lapping 30year time-slices and three emissions scenarios, only the 2080s time-slice (2070-2099) and the Medium (A1B) emissions scenario are used here. The 2080 s time-slice is chosen as this is the latest one, so allows for the largest anthropogenic climate changes relative to natural climate variability. The A1B emissions scenario is chosen as the RCM ensemble data are only available for this emissions scenario.

\subsubsection{Methods of application}

There are two alternative types of application: a) change factors and b) timeseries. The Sampled Data are supplied as change factors, whereas the Weather Generator produces time-series based on the Sampled Data. The $\mathrm{RCM}$ ensemble data are available as time-series, which can be used to produce monthly change factors. The RCM ensemble data will thus be applied in both ways, for comparison.

The change factor method involves the application of monthly (percentage or absolute) changes in a variable to a baseline time-series for that variable. In this 
case the baseline comprises the observed daily precipitation and mean temperature time-series and the MORECS PE time-series for the period 19612001. Here, the monthly change factors are applied equally to each day of the relevant month (although more complex applications are possible, see for example Prudhomme et al. 2002). That is, the monthly percentage changes given for precipitation (or PE) are applied to each day of the corresponding month in the observed precipitation (or PE) time-series, and the monthly absolute changes given for temperature are added to each day of the corresponding month in the observed temperature time-series. Note that the Sampled Data change factors use 1961-1990 as the baseline period, thus applying them to observed data for the period 1961-2001 is not strictly correct, but allows for greater natural climatic variability.

A summary of the four methods of application of UKCP09 data, including the two types of application for the RCM ensemble data, is given in Table 2. Some of the choices within each application are described in Section 2.3.2.

\subsubsection{Choices}

Using each of the UKCP09 products involves choices about exactly what to apply and how. Some of these choices are discussed below, along with details on what has been done here and why.

1. Sampled Data change factors (Method 1: SD-CF);

i. Sub-samples of the full Sampled Data can be requested, based on either random selection (with replacement) or through specifying Sample Id numbers. The full set of 10,000 has been used here, for completeness.

ii. The Sampled Data for any location in the UK can be obtained for a) boxes on an approximately $25 \times 25 \mathrm{~km}$ grid (that of the RCM, for those boxes categorised as 'land'), b) 16 administrative regions or c) 23 river-basin regions (Murphy et al. 2009, Figure 1.2). Here, Sampled Data for relevant grid boxes have been used (see below).

iii. When applying the Sampled Data, it is important to note that they are not spatially coherent (Murphy et al. 2009, Annex 4). That is, line $n$ of change factors for a given grid box cannot be considered to coincide with line $n$ of change factors for any neighbouring grid box. This means that, for a lumped catchment model, it is not possible to average the Sampled Data across all grid boxes covering a catchment to obtain an average set of Sampled Data for the catchment. Similarly, it is not possible to apply different change factors to different parts of a catchment modelled with a (semi-)distributed hydrological model. Instead, a single set of Sampled Data has to be chosen for each catchment (e.g. that for one grid box or for the appropriate river-basin region). Here, the single set of Sampled Data applied is that from the grid box containing the catchment centroid (Table 3).

iv. When applying the Sampled Data, it is also important to note that the variables have been processed for UKCP09 in two separate batches and that data are not coherent between these batches (see Murphy et al. 2009, Annex 4). That is, line $n$ of change factors for a variable in batch 1 cannot be considered to coincide with line $n$ of change factors for a variable in batch 2 . One consequence of this is that formulations of $P E$ requiring surface radiation data, such as the often-used Penman-Monteith 
formulation (Monteith 1965), cannot be applied in a standard way as the short wave and long wave flux terms are in batch 2 whereas temperature is in batch 1 (see Murphy et al. 2009, Table A.2). Formulations using relative humidity and/or cloud as well as temperature could be applied, as these variables are all in batch 1 . Here, for simplicity, a purely temperature-based formulation has been applied (Oudin et al. 2005), and the baseline and adjusted temperature time-series used to estimate monthly percentage changes in PE corresponding to each line of Sampled Data. These PE change factors have then been applied to the baseline (MORECS) PE data for the catchment in order to derive future PE data for input to the hydrological model.

2. Weather Generator time-series (Method 2: WG-TS);

i. The Weather Generator is set-up on a $5 \times 5 \mathrm{~km}$ grid over Britain and, similar to $1 \mathrm{iii}$ above, separate runs for neighbouring grid boxes are not spatially coherent. However, the weather generator does allow the selection of multiple adjoining squares (up to an area of $1000 \mathrm{~km}^{2}$, or 40 squares), for which it can be run to produce a single time-series for the selected area for each variable. As stated in the weather generator report (Jones et al. 2009, Section 5.3), "Care must be taken in the interpretation of this series however, as it still corresponds to a single point but one which is representative, on average, of the region. The weather generator variables in the series are not areal-averaged values". Here, a set of adjoining $5 \times 5 \mathrm{~km}$ squares has been chosen to cover each catchment (Table 3 ), and the time-series produced for the chosen region have been used directly to drive the PDM hydrological model for the catchment. This seems to be the best way to get the input time-series required by the PDM, although ideally the weather generator would be capable of producing spatially consistent time-series which could be used to produce catchment-average inputs.

ii. The Weather Generator can be used to produce a specified number of runs $(N)$. Generally, the $N$ runs correspond to a random choice of $N$ of the 10,000 Sampled Data change factors (with replacement), but $N$ is limited to a maximum of 1000 (to limit the volume of data produced), and a minimum of 100 (considered the smallest number of samples allowable to maintain the probabilistic nature of the data). Here, the minimum of 100 time-series are used for each catchment. It should be noted that rerunning the weather generator to produce 100 more runs for the same location will generally produce quite different climatic time-series (unless the same initial seed is specified), and thus lead to a potentially different set of impacts. However, tests suggested that any error introduced in the distribution of flood frequency impacts by using 100 rather than 1000 runs is rather less than the probabilistic impact range (Kay et al. 2011b). Note that time-series can also be requested for specific, rather than randomly selected, change factors if required (sampling by Sample Id number; although re-running without specifying the same initial seed would still lead to different climatic time-series).

iii. The Weather Generator can be used to produce (stationary) daily timeseries of length $L$, where $L$ can be a minimum of 30 years and a maximum of 100 years, or any multiple of 10 within this range. Here, only runs of 30 years have been applied, as this is the standard time-slice length for climate analyses and is consistent with the length of the RCM time-series 
used and with the length of observed data often available. Tests suggested that using longer time-series did not lead to significantly different distributions for the flood frequency impacts, particularly in terms of the median impact (Kay et al. 2011b).

iv. In the change factor method only a single baseline is available (observed time-series data). However, the Weather Generator gives a set of $N$ possible baselines (representing natural variability as characterised in the observed data used to construct the weather generator) as well as $N$ possible futures (representing uncertainty in various aspects of climate change as well as natural variability). Thus the question arises of which baseline to use with each future, when calculating the impacts. Here, while baseline $i$ of $N$ has been used with future $i$ of $N$, for $i$ in $(1, \ldots, N)$, this is not strictly necessary since the baseline is purely a natural variability ensemble - none of the parameters of the weather generator have been changed (in contrast to the RCM baseline ensemble, see discussion in 3iv below).

3. RCM ensemble data (Methods $3 a$ and $3 b$ : RCM-CF and RCM-TS);

i. For each catchment, the RCM-derived change factors (Method 3a) are taken from the grid box containing the catchment centroid (Table 3), just as for the Sampled Data change factors (Method 1). The difference when applying RCM-derived change factors as against Sampled Data change factors is that the former are spatially coherent, and thus could be used to apply different changes to inputs in different parts of a large catchment modelled with a (semi-)distributed model.

ii. The only PE time-series data available directly from the RCM are 'openwater' PE. These can be transformed into time-series of PE from a vegetated surface in a way which emulates the often-used PenmanMonteith PE formulation (Monteith 1965), using other variables available from the RCM (Bell et al. 2011). These estimates of vegetated-surface PE are then used to provide both the PE change factors for Method $3 a$ (RCM$\mathrm{CF}$ ) and the PE time-series for Method 3b (RCM-TS).

iii. When the actual RCM time-series for the baseline (1961-1990) and future (2070-2099) time-slices are used to run the hydrological model (Method 3b: RCM-TS), it is necessary to produce time-series of catchment-average precipitation and PE data from the gridded RCM data. This is done using the method of Kay et al. (2006b), whereby the catchment boundary is overlaid on the RCM grid and area-weighting used, in combination with weighting using Standard Average Annual Rainfall (SAAR) data for precipitation. The temperature time-series applied is simply that for the grid box containing the catchment centroid, which is used in the snowmelt module along with information on the average altitude of the grid box from the RCM orography file.

iv. When the actual RCM time-series are used to run the hydrological model (Method 3b: RCM-TS), the baseline time-slice and future time-slice pair for each ensemble member should be kept together when calculating the impacts. This is to ensure that results from comparable approximations of the present and future climate (i.e. each from a model with the same set of parameters) are used to calculate the impact of the change between these simulated present and future climates. 


\subsection{Comparison of baselines and climatic changes}

Figure 2 shows, for each of the nine catchments, the three different sets of baseline flood frequency curves used (see Table 2). These are:

- Observed baseline: The single flood frequency curve simulated with observed data, which is used with Methods 1 and $3 a$ (SD-CF and RCM$\mathrm{CF})$.

- Weather Generator baselines: The range of flood frequency curves simulated using weather generator baseline data, which are used with Method 2 (WG-TS; see point 2iv in Section 2.3.2).

- RCM baselines: The 11 flood frequency curves simulated using RCM data for the baseline period, which are used with Method 3b (RCM-TS; see point 3iv in Section 2.3.2).

The plots show relatively good agreement between these sets of baseline flood frequencies. The clearest difference between the baselines occurs for catchment 38003, where the weather generator baselines are relatively low compared to the observed baseline, whereas the $11 \mathrm{RCM}$ baselines are higher than the observed baseline. The absolute differences are small however, as the flow peaks themselves are small. It should be noted that very close agreement should not expected between either weather generator or RCM baselines and the observed baseline, since such simulated baselines include aspects of natural variability. This is particularly the case for the RCM baselines, as the RCM runs include multi-decadal natural variability as well as the shorter term variability included in the weather generator runs (Kendon et al. 2008, Räisänen and Ruokolainen 2006).

Figure 3 shows the monthly Sampled Data change factors and RCM-derived change factors for each catchment, for precipitation, temperature and PE. These plots show that, for precipitation and temperature, the 11 RCM-derived changes are (almost) always within the range of the 10,000 Sampled Data changes for each month. However, the 11 RCM-derived changes are not necessarily fully representative of the Sampled Data distributions, particularly for temperature where they appear to be biased towards larger increases in summer for more southerly catchments (e.g. 43005, 47007 and 54008) and in winter for more northerly catchments (e.g. 02001, 07002 and 14001). The latter could affect the results through greater changes in snow processes.

For PE, Figure 3 shows that the RCM-derived changes are more variable relative to the changes derived for the Sampled Data. This could be due to the use of the purely temperature-based PE scheme with the Sampled Data, whereas the RCM PE changes take account of changes in other atmospheric variables like humidity and wind speed. However, the largest differences occur in winter, where even large percentage changes in PE are not significant since the baseline PE is very small. Although the choice of PE scheme is an additional source of uncertainty in the hydrological modelling, the effect of this is smaller for the high flows modelled here than for lower flows, and is also likely to be small relative the range of climate modelling uncertainty (Kay and Davies 2008).

\section{Results}

Figure 4 shows the results for one catchment, the Yealm@Puslinch (47007), in terms of percentage changes in flood peaks at two return periods; 2-years and 
20-years (that is, the peak flow that would be expected to be exceeded, on average, once every 2 years or once every 20 years). The range of impacts for Method 1 (SD-CF) and Method 2 (WG-TS) are plotted as histograms (Figure 4a) and cumulative distribution functions (cdfs; Figure 4b). Also shown are the 11 individual results for Methods $3 a$ and $3 b$ (RCM-CF and RCM-TS), plotted as symbols below the zero $x$-axis, at the correct $x$-position for each modelled impact.

The plots in Figure 4 show considerable similarity in the average results from each of the four methods, with their medians all within about $10 \%$ of each other (within 5\% at the 2-year return period). When comparing the distributions from Methods 1 and 2 (SD-CF and WG-TS) with the 11 individual RCM ensemble data results from Methods $3 a$ and $3 b$ (RCM-CF and RCM-TS), the minimum $\mathrm{RCM}$ result might be expected to lie close to the $10^{\text {th }}$ percentile of the range, with the maximum $\mathrm{RCM}$ result close the $90^{\text {th }}$ percentile of the range (if the RCM ensemble is providing a good coverage of the range of uncertainty). In comparing the two change factor applications, the minimum impacts from Method 3a (RCM-CF) fit relatively well with the $10^{\text {th }}$ percentile impacts from Method 1 (SD-CF), although the maximum impact from Method 3a (RCM-CF) seems to underestimate the $90^{\text {th }}$ percentile from Method 1 (SD-CF), particularly at the 20-year return period. In comparing the two time-series applications, the minimum (maximum) impacts from Method $3 b$ (RCM-TS) fit relatively well (within 10\%) with the $10^{\text {th }}\left(90^{\text {th }}\right)$ percentile impacts from Method 2 (WG-TS).

Also shown in Figure 4 are lines connecting the equivalent results from Methods $3 a$ and $3 b$ (that is, those derived using the same RCM ensemble member for RCM-CF and RCM-TS). These show that there is considerable cross-over in results when information from the same ensemble member is applied in different ways - the ordering of the ensemble member impacts when the change factors are applied (RCM-CF) is not the same as the ordering when the time-series are applied (RCM-TS). This is discussed later.

The results for all nine catchments are summarised in Figure 5, where box-andwhisker plots are used to summarise the distributions for Methods 1 and 2 (SDCF and WG-TS). These show that, for most catchments, there is a reasonable correspondence between the results from each of the methods. That is, there is generally considerable overlap between the distributions from Methods 1 and 2 (SD-CF and WG-TS) and the 11 individual results from Methods $3 \mathrm{a}$ and $3 \mathrm{~b}$ (RCM-CF and RCM-TS), with the four median values for a catchment generally within $10 \%$ or so of each other, and the $10^{\text {th }}\left(90^{\text {th }}\right)$ percentiles often fitting relatively well with the minima (maxima) from the equivalent $\mathrm{RCM}$-based results.

The main exception to this is catchment 07002 at the 20 -year return period, where the median from Method 2 (WG-TS) sits around $20 \%$ higher than the medians from the other methods (RCM-TS, RCM-CF and SD-CF). Moreover, the $25^{\text {th }}$ percentile from Method 2 (WG-TS) sits above the $75^{\text {th }}$ percentile from Method 1 (SD-CF). Since catchment 07002 is, by virtue of its location, the most affected by snowfall / snowmelt of the nine catchments, initially it was speculated that the difference could be due to threshold effects in snowmelt modelling when using weather generator temperature data. However, this 
proved incorrect, since re-running the hydrological model without the snowmelt module led to no appreciable change in the set of impacts (not shown). Similarly, producing 100 new sets of weather generator time-series for catchment 07002, and re-running the hydrological model, led to no appreciable change in the set of impacts (not shown). An analysis of the daily rainfall simulated by the weather generator for catchment 07002 showed that the average number of days per year with extreme rainfall $(>20 \mathrm{~mm})$ increased by 2.5 days, from 6.5 days in the baseline period to 9 days in the future period. This is likely to be the reason for the larger increase in 20-year return period flood peaks using Method 2 (WG-TS) than Method 3b (RCM-TS) for catchment 07002, as the RCM rainfall time-series for this catchment show a smaller increase in the average number of days with extreme rainfall (1.4 days). For the other eight catchments, the increase in the number of extreme rainfall days from the weather generator is much more similar (in percentage terms) to that from the RCM. This apparent discrepancy for catchment 07002 could be due to the use of the weather generator for a region of more variable topography (Table 1), as the spatial averaging of the weather generator coefficients could result in rainfall time-series not fully representative of catchment-average rainfall. This is discussed further in Section 4.

Other notable differences in results include those for catchment 34003 (at the 2year return period), where the RCM-based changes (Methods $3 \mathrm{a}$ and $3 \mathrm{~b}$ : RCMCF and RCM-TS) sit higher than the bulk of those for the other two methods. This suggests that, for this catchment, the climatic changes simulated by the $\mathrm{RCM}$ ensemble are not representative of the broader set of changes in the expanded GCM ensemble used as the basis for the Sampled Data and the Weather Generator time-series. Also, for catchment 38003 (at the 2-year return period), the time-series results (Methods 2 and 3b: WG-TS and RCM-TS) sit higher than the change factor results (Methods 1 and 3a: SD-CF and RCM-CF). This suggests that, for this catchment, the enhanced variability from use of generated or RCM simulated baseline and future time-series is important. This feature is also seen in the upper end of the range of changes for the 20-year return period events.

For almost all catchments and methods, the range of uncertainty is higher at the 20-year return period than at the 2-year return period (perhaps unsurprisingly). The only exceptions are for Method 3a (RCM-CF), for catchments 34003 and 47007. Also, the range of uncertainty from Method 2 (WG-TS) is generally greater range than that from Method 1 (SD-CF), and the range from Method $3 \mathrm{~b}$ (RCM-TS) is often greater than from Method 3a (RCM-CF), which is to be expected given the restrictions of change factor methods in terms of changes in variability, the number of wet days and the sequencing of events (Diaz-Nieto and Wilby 2005). Also, the time-series methods as applied here include natural variability in their baselines (Figure 2) as well as their futures, which is likely to inflate their impact ranges.

Overall though, there is more difference in results for different catchments than there is in results from different methods applied to the same catchment. These differences in impacts between catchments could be related to catchment location (i.e. be due to spatial variation in the climate change signal itself), or be due to physical catchment properties (i.e. catchments with different properties 
are likely to propagate the same climatic changes through to different impacts; see Prudhomme et al. 2010). Most likely, the differences in impacts between catchments are due to a combination of both of these factors.

Also shown in Figure 5 are lines connecting the equivalent results from Methods $3 a$ and $3 b$ (that is, those derived using the same RCM ensemble member for RCM-CF and RCM-TS). These show that, for all catchments, there is considerable cross-over in results when information from the same ensemble member is applied in different ways, as discussed for catchment 47007 (Figure 4). This is not actually that surprising, since it is simply a demonstration of the effects of natural variability. To demonstrate this, the RCM-derived change factors have been applied to alternative baseline time-series, for three of the nine catchments (02001, 43005 and 47007). The results (Figure 6) show the same sort of cross-over occurring. Here, nine alternative baselines have been constructed by resampling the observed baseline in 1-month blocks; the results look very similar when the baseline time-series from each RCM ensemble member are used as 11 alternative baselines (not shown).

The plots in Figure 6 also show how the specifics of the baseline time-series matter more for some catchments than others, in terms of the impact under given sets of change factors (in this case the $11 \mathrm{RCM}$-derived change factors). For example, the median impact is more dependent on the baseline used for catchment 02001 than it is for either catchment 43005 or 47007 ; it varies from about $-5 \%$ to $+25 \%$ for catchment 02001 , but only from $+5 \%$ to $+20 \%$ for catchment 43005 and from $+14 \%$ to $+24 \%$ for catchment 47007 . Furthermore, there is much more consistent overlap between the set of impacts using alternative baselines for catchments 43005 and 47007 than for catchment 02001. It is notable that, for catchment 02001, the minimum impact using resample 8 exceeds the maximum impact using resample 2. As the resampled baselines allow variation in multi-month accumulations (Kay et al. 2009b), Figure 6 demonstrates the varying effect of this type of baseline natural variability when using change factors to investigate the impacts on flood peaks.

\section{Discussion}

This paper has compared the use of three UKCP09 products (Sampled Data, Weather Generator time-series and RCM ensemble data), to provide inputs for modelling the impacts of climate change on flood frequency in nine catchments across Britain. The results showed relatively good agreement between methods for most catchments when looking at the median changes. There are also differences, probably the most important being that the use of time-series generally leads to a greater range of impacts than when using change factors. This reinforces the important point that using change factors does not allow any account to be taken of the effects of variability, either natural variability (as represented in the Weather Generator) or both natural and changes in variability (as represented in the RCMs).

Other differences include the use of Weather Generator time-series leading to much higher impacts than the other methods for one catchment (07002). It is suggested that this is due to the weather generator producing rainfall timeseries that are not fully representative of the catchment-average for regions of highly variable topography. The weather generator report (Jones et al. 2009, 
Section 5.3) states that, when producing time-series for regions, "Care must also be taken that a homogeneous region is chosen, avoiding for example, large differences in elevation". For such regions, a weather generator capable of producing spatially consistent time-series (e.g. Burton et al. 2008) would be preferable, as such time-series could be used to produce catchment-average inputs in the same way that gauged rainfall data are used to make observed catchment-average time-series.

The results imply that climate impact studies should not necessarily rely on the application of just one UKCP09 product, as each product has different strengths and weaknesses. Whilst the Sampled Data provide the most comprehensive coverage of climate modelling uncertainty currently available, the range of impacts modelled using these will not necessarily fully encompass the range modelled using other methods. In particular, the application of the Sampled Data to fixed climatic baseline time-series does not allow for the effects of variability, at various time-scales, which require the application of the timeseries methods. However, time-series methods rely on the ability of (climate or weather generator) models to produce appropriate climatic inputs. Furthermore, the difference in the ranges from the different methods may depend on location or on the system being modelled, and different impact applications will have different data requirements and priorities, which have to be borne in mind. In addition, the impacts for some applications may be more dependent on the baseline used with change factors methods than other applications. It should also be noted that the impact ranges shown here are likely to under-estimate the full ranges, as hydrological model structure and parameter uncertainty has not been included. However, a number of studies have shown that uncertainty from these sources is generally smaller than that from climate models (e.g. Kay et al. 2009b, New et al. 2007, Wilby and Harris 2006).

The probabilistic projections from UKCP09 have been a big step forward for impact studies, as they provide for a risk-based approach to decision-making under climate change. For example, a decision-maker could decide to provide a level of protection equivalent to the $75^{\text {th }}$ percentile impact (i.e. to protect against the impacts from $75 \%$ of the climate projections). Such percentile thresholds can be read from cdfs (or boxplots), like those presented in Figure 4b (or Figure 5) for Methods 1 and 2. Such an approach is difficult to achieve by modelling impacts for only a small set of scenarios, with no weights indicating the relative likelihood of those scenarios (like the RCM results presented in Figure 4 and Figure 5).

However, it is important to note that, even given UKCP09's more comprehensive exploration of uncertainty in future climate than any previous climate modelling study, the results are still conditional on available data and resources. That is, the probabilities given by UKCP09 represent "the relative degree to which each possible climate outcome is supported by the evidence available, taking into account our current understanding of climate science and observations, as generated by the UKCP09 methodology." (Murphy et al. 2009, Section 1.1.1). As New et al. (2007) point out (with reference to their use of the climateprediction.net ensemble), even with a more comprehensive methodology, "with more data, more resources or an alternative experimental design, the likelihoods will not be the same, though they may or may not be 
similar". This means that there needs to be a continual process of improving our understanding of the climate system, improving our (climate and impacts) modelling, and re-assessing the potential impacts. Thus decision-making processes must be based around flexible options, allowing for future changes to projections and to methodologies to interpret and apply these.

Improving the representation of uncertainty should, preferably, not simply be a matter of making larger and larger climate ensembles, as many subsequent impact models are themselves simply too complex to enable them to be run with inputs derived from such large ensembles (at least without the availability of a significant computing resource). Where it is infeasible to run large ensembles of climate projections through impact models, it may be necessary to select a small subset of projections, but such selection would have to be done with great care and would upset the probabilistic nature of the resulting impacts. Alternatively, the impact modelling side could be developed to enable easier use of large ensembles. This could be done via the development of statistical emulators (Rougier 2008) for the impact models, as was done for the climate models in UKCP09, or via the development of impact response surfaces using a sensitivity framework approach (e.g. Prudhomme et al. 2010).

\section{Acknowledgements}

This research was supported by the Joint Department of Energy and Climate Change (DECC) and Department for Environment Food and Rural Affairs (Defra) Met Office Hadley Centre Climate Programme - DECC/Defra (GA01101). The UK Climate Projections data have been made available by the Department for Environment, Food and Rural Affairs (Defra) and Department for Energy and Climate Change (DECC) under licence from the Met Office, Newcastle University, University of East Anglia and Proudman Oceanographic Laboratory. These organisations accept no responsibility for any inaccuracies or omissions in the data, nor for any loss or damage directly or indirectly caused to any person or body by reason of, or arising out of, any use of this data. Three anonymous reviewers are thanked for their comments, which helped to improve this paper.

\section{References}

Bell, VA, Gedney, N, Kay, AL, Smith, R, Jones, RG, Moore, RJ (2011) Estimating potential evaporation from vegetated surfaces for water management impact assessments using climate model output. Journal of Hydrometeorology, 12, 1127-1136.

Bell, VA, Kay, AL, Jones, RG, Moore, RJ, Reynard, NS (2009) Use of soil data in a grid-based hydrological model to estimate spatial variation in changing flood risk across the UK. Journal of Hydrology, 377(3-4), 335-350, doi: 10.1016/j.jhydrol.2009.08.031.

Bell, VA, Moore RJ (1999) An elevation-dependent snowmelt model for upland Britain. Hydrological Processes, 13, 1887-1903.

Burton, A, Kilsby, CG, Fowler, HJ, Cowpertwait, PSP, O'Connell, PE (2008) RainSim: A spatial temporal stochastic rainfall modelling system. Environ. Mod. Soft., 23 (12), 1356-1369, doi:10.1016/j.envsoft.2008.04.003

Crooks, SM, Kay, AL, Reynard, NS (2009) Regionalised impacts of climate change on flood flows: hydrological models, catchments and calibration. Report to Department for Environment, Food and Rural Affairs, FD2020 project milestone, CEH Wallingford, November 2009, 59pp.

Dettinger, MD, Cayan, DR, Meyer, MK, Jeton, AE (2004) Simulated hydrologic responses to climate variations and change in the Merced, Carson, and American river basins, Sierra Nevada, California, 1900-2099. Climatic Change, 62, 283-317. 
Diaz-Nieto, J, Wilby, RL (2005). A comparison of statistical downscaling and climate change factor methods: impacts on low flows in the River Thames, United Kingdom. Climatic Change, $69,245-268$.

Frame, DJ, Aina, T, Christensen, CM, Faull, NE, Knight, SHE, Piani, C, Rosier, SM, Yamazaki, K, Yamazaki Y, Allen, MR (2009) The climateprediction.net BBC climate change experiment: design of the coupled model ensemble. Phil. Trans. R. Soc. A, 367, 855-870; doi:10.1098/rsta.2008.0240

Graham, LP, Hageman, S, Jaun, S, Beniston, M (2007) On interpreting hydrological change from regional climate models. Climatic Change, 81, 97-122.

IPCC (2000) Special report on emissions scenarios (SRES): A special report of Working Group III of the Intergovernmental Panel on Climate Change. Cambridge University Press, Cambridge, $599 \mathrm{pp}$.

IPCC (2007) Climate Change 2007: Synthesis Report. Contribution of Working Groups I, II and III to the Fourth Assessment Report of the Intergovernmental Panel on Climate Change [Core Writing Team, Pachauri, RK and Reisinger, A (eds.)]. IPCC, Geneva, Switzerland, 104pp.

Jenkins, GJ, Cooper, C, Hassell, DC, Jones, RG (2003) Scenarios of climate change for islands within the BIC region, British-Irish Council Report, 2003.

Jenkins, GJ, Perry, MC, Prior, MJO (2007) The climate of the United Kingdom and recent trends. Met Office Hadley Centre, Exeter, UK.

Jones, PD, Kilsby, CG, Harpham, C, Glenis, V, Burton, A (2009) UK Climate Projections science report: Projections of future daily climate for the UK from the Weather Generator. University of Newcastle, UK.

Kay, AL, Crooks, S, Prudhomme, C (2009a) Regionalised impacts of climate change on flood flows: Uncertainty analysis. Report to Department for Environment, Food and Rural Affairs, FD2020 project milestone, CEH Wallingford, November 2009, 71pp.

Kay, AL, Crooks, SM, Pall, P, Stone, D (2011a). Attribution of Autumn/Winter 2000 flood risk in England to anthropogenic climate change: a catchment-based study. Journal of Hydrology, 406, 97-112, doi: 10.1016/j.jhydrol.2011.06.006.

Kay, AL, Crooks, SM, Reynard, NS, Lamb, R (2011b). Translating UKCP09: FCERM-specific projections. Report to Environment Agency, SC080004/R/FCERM Projections, June 2011, 32pp.

Kay, AL, Davies, HN (2008). Calculating potential evaporation from climate model data: a source of uncertainty for hydrological climate change impacts. Journal of Hydrology, 358, 221239, doi: 10.1016/j.jhydrol.2008.06.005.

Kay, AL, Davies, HN, Bell, VA, Jones, RG (2009b) Comparison of uncertainty sources for climate change impacts: flood frequency in England. Climatic Change, 92(1-2), 41-63, doi: $10.1007 / \mathrm{s} 10584-008-9471-4$.

Kay, AL, Jones, DA, Crooks, SM, Kjeldsen, TR, Fung, CF (2007) An investigation of sitesimilarity approaches to generalisation of a rainfall-runoff model. Hydrology and Earth System Sciences, 11, 500-515.

Kay, AL, Jones, RG, Reynard, NS (2006a) RCM rainfall for UK flood frequency estimation. II. Climate change results. Journal of Hydrology, 318, 163-172.

Kay, AL, Reynard, NS, Jones, RG (2006b) RCM rainfall for UK flood frequency estimation. I. Method and validation. Journal of Hydrology, 318, 151-162. 
Kendon, EJ, Jones, RG, Kjellstrom, E, Murphy, JM (2010) Using and designing GCM-RCM ensemble regional climate projections. Journal of Climate, 23, 6485-6503, doi: 10.1175/2010JCLI3502.1

Kendon, EJ, Rowell, DP, Jones, RG, Buonomo, E (2008) Robustness of Future Changes in Local Precipitation Extremes. Journal of Climate, 21, 4280-4297, doi: 10.1175/2008JCLI2082.1

Monteith, JL (1965) Evaporation and environment. Symposia of the Society for Experimental Biology, 19, 205-234.

Moore, RJ (1985) The probability-distributed principle and runoff production at point and basin scales. Hydrolog. Sci. J., 30, 273-297.

Moore, RJ (2007) The PDM rainfall-runoff model. Hydrology and Earth System Sciences, 11(1), 483-499.

Moore, RJ, Bell, VA, Jones, DA (2005) Forecasting for flood warning. C.R. Geoscience, 337, 203-217.

Murphy, JM, Sexton, DM, Barnett, DN, Jones, GS, Webb, MJ, Collins, M, Stainforth DA (2004) Quantification of modelling uncertainties in a large ensemble of climate change simulations. Nature, 430, 7001, 768-772

Murphy, JM, Sexton, DMH, Jenkins, GJ, Booth, BBB, Brown, CC, Clark, RT, Collins, M, Harris, GR, Kendon, EJ, Betts, RA, Brown, SJ, Humphrey, KA, McCarthy, MP, McDonald, RE, Stephens, A, Wallace, C, Warren, R, Wilby, R, Wood, RA (2009) UK Climate Projections Science Report: Climate change projections. Met Office Hadley Centre, Exeter.

Naden, PS (1992) Analysis and use of peaks-over-threshold data in flood estimation. In: AJ Saul (Ed.) Floods and Flood Management, Kluwer Academic, Dordrecht, 131-143.

New, M, Lopez, A, Dessai, S, Wilby, R (2007) Challenges in using probabilistic climate change information for impact assessments: an example from the water sector. Philosophical Transactions of the Royal Society A, 365, 2117-2131.

Oudin, L, Hervieu, F, Michel, C, Perrin, C, Andreassian, V, Anctil, F, Loumagne, C (2005) Which potential evapotranspiration input for a lumped rainfall-runoff model?: Part 2 - Towards a simple and efficient potential evapotranspiration model for rainfall-runoff modelling. Journal of Hydrology, 303(1-4): 290-306.

Pall, P, Aina, T, Stone, DA, Stott, PA, Nozawa, T, Hilberts, AGJ, Lohmann, D, Allen, MR (2011) Anthropogenic greenhouse gas contribution to flood risk in England and Wales in autumn 2000. Nature, 470, 382-386.

Prudhomme, C, Davies, HN (2009) Assessing uncertainties in climate change impact analyses on river flow regimes in the UK. Part 2: future climate. Climatic Change, 93, 197-222, doi: 10.1007/s10584-008-9461-6.

Prudhomme, C, Reynard, N, Crooks, S (2002) Downscaling from global climate models for flood frequency analysis: where are we now? Hydrological Processes, 16, 1137-1150.

Prudhomme, C, Wilby, RL, Crooks, S, Kay, AL, Reynard, NS (2010). Scenario-neutral approach to climate change impact studies: Application to flood risk. Journal of Hydrology, 390, 198-209, doi: 10.1016/j.jhydrol.2010.06.043.

Räisänen, J, Ruokolainen, L, (2006). Probabilistic forecasts of near-term climate change based on a resampling ensemble technique. Tellus $A, 58,461-472$.

Reynard, NS, Crooks, S, Kay, AL, Prudhomme, C (2009) Regionalised impacts of climate change on flood flows. Report to Department for Environment, Food and Rural Affairs, Technical Report FD2020, CEH Wallingford, November 2009, 113pp. 
Rougier, JC (2008) Efficient Emulators for Multivariate Deterministic Functions, Journal of Computational and Graphical Statistics, 17(4), 827-843. doi:10.1198/106186008X384032

Thompson, N, Barrie, IA, Ayles, M (1982) The Meteorological Office Rainfall and Evaporation Calculation System: MORECS (July 1981). Hydrological Memorandum No. 45, Met Office, Bracknell.

Wilby, RL, Harris, I (2006) A framework for assessing uncertainties in climate change impacts: Low-flow scenarios for the River Thames, UK. Water Resources Research, 42, W02419, doi:10.1029/2005WR004065. 


\section{Tables}

Table 1 Detail of the nine catchments.

\begin{tabular}{|c|c|c|c|c|c|}
\hline $\begin{array}{l}\text { Catchment } \\
\text { Number }\end{array}$ & River name & Location & $\begin{array}{l}\text { Catchment } \\
\text { Area }\left(\mathrm{km}^{2}\right)\end{array}$ & $\begin{array}{l}\text { Median altitude } \\
\text { (range) (masl) }\end{array}$ & $\begin{array}{l}\text { SAAR }_{61-90} \\
(\mathrm{~mm})\end{array}$ \\
\hline 02001 & Helmsdale & Kilphedir & 551.4 & $\begin{array}{r}200 \\
(17-689)\end{array}$ & 1117 \\
\hline 07002 & Findhorn & Forres & 781.9 & $\begin{array}{r}408 \\
(10-935)\end{array}$ & 1064 \\
\hline 14001 & Eden & Kemback & 307.4 & $\begin{array}{r}100 \\
(6-520)\end{array}$ & 799 \\
\hline 21023 & Leet Water & Coldstream & 113.0 & $\begin{array}{r}74 \\
(12-221)\end{array}$ & 671 \\
\hline 34003 & Bure & Ingworth & 164.7 & $\begin{array}{r}48 \\
(12-104)\end{array}$ & 669 \\
\hline 38003 & Mimram & Panshanger Park & 133.9 & $\begin{array}{r}122 \\
(47-193)\end{array}$ & 656 \\
\hline 43005 & Avon & Amesbury & 323.7 & $\begin{array}{r}129 \\
(67-294)\end{array}$ & 745 \\
\hline 47007 & Yealm & Puslinch & 54.9 & $\begin{array}{r}124 \\
(6-490)\end{array}$ & 1410 \\
\hline 54008 & Teme & Tenbury & 1134.4 & $\begin{array}{r}214 \\
(48-545)\end{array}$ & 841 \\
\hline
\end{tabular}

Table 2 Summary of methods.

\begin{tabular}{|c|c|c|c|}
\hline $\begin{array}{l}\text { Method } \\
\text { Number }\end{array}$ & $\begin{array}{l}\text { Method name } \\
\text { (shorthand) }\end{array}$ & $\begin{array}{l}\text { Sample } \\
\text { size }\end{array}$ & Brief description \\
\hline 1 & $\begin{array}{l}\text { Sampled Data } \\
\text { change } \\
\text { factors } \\
\text { (SD-CF) }\end{array}$ & 10,000 & $\begin{array}{l}\text { Observed baseline daily time-series (1961-2001) used to } \\
\text { run hydrological model, and flood frequency curve fitted } \\
\text { to simulated flows to make baseline flood frequency. } \\
\text { Then observed baseline time-series adjusted using each } \\
\text { set of change factors (PE changes not available, so } \\
\text { estimated using temperature changes). Resulting } \\
\text { adjusted time-series used to run hydrological model, and } \\
\text { flood frequency curves fitted to simulated flows to } \\
\text { produce possible future flood frequencies. Percentage } \\
\text { change in flood peaks calculated between baseline flood } \\
\text { frequency curve and future curves. }\end{array}$ \\
\hline 2 & $\begin{array}{l}\text { Weather } \\
\text { Generator } \\
\text { time-series } \\
\text { (WG-TS) }\end{array}$ & 100 & $\begin{array}{l}\text { One baseline (1961-1990) and one future (2070-2099) } \\
\text { set of daily time-series for each Weather Generator run } \\
\text { (daily minimum and maximum temperature averaged to } \\
\text { make daily mean temperature). Each pair used to run } \\
\text { hydrological model, and flood frequency curves fitted to } \\
\text { simulated flows. Percentage change in flood peaks } \\
\text { calculated between corresponding pairs of baseline and } \\
\text { future flood frequency curves. }\end{array}$ \\
\hline $3 a$ & $\begin{array}{l}\text { RCM-derived } \\
\text { change } \\
\text { factors } \\
\text { (RCM-CF) }\end{array}$ & 11 & $\begin{array}{l}\text { Change factors derived from RCM baseline and future } \\
\text { time-series (see below) for each ensemble member, for } \\
\text { precipitation, mean temperature and PE. Hydrological } \\
\text { model run as for Method } 1 .\end{array}$ \\
\hline $3 b$ & $\begin{array}{l}\text { RCM time- } \\
\text { series } \\
\text { (RCM-TS) }\end{array}$ & 11 & $\begin{array}{l}\text { One baseline (1961-1990) and one future (2070-2099) } \\
\text { set of daily time-series for each RCM ensemble member } \\
\text { Hydrological model run as for Method } 2 \text {. }\end{array}$ \\
\hline
\end{tabular}


Table 3 Grid boxes used for Sampled Data and Weather Generator time-series data for each of the nine catchments.

\begin{tabular}{|c|c|c|c|}
\hline $\begin{array}{l}\text { Catchment } \\
\text { Number }\end{array}$ & $\begin{array}{l}\text { Sampled } \\
\text { Data } \\
\text { grid box } \\
\text { numbers }\end{array}$ & $\begin{array}{l}\text { Number of } \\
5 \times 5 \mathrm{~km} \\
\text { weather } \\
\text { generator } \\
\text { grid boxes }\end{array}$ & Weather Generator grid box numbers \\
\hline 02001 & 0378 & 22 & $\begin{array}{l}\text { 2750945, 2800945, 2750940, 2800940, 2850940, } 2900940, \\
2750935,2800935,2850935,2900935,2950935,2800930, \\
\text { 2850930, 2900930, 2950930, 2850925, 2900925, 2950925, } \\
3000925,2900920,2950920,3000920\end{array}$ \\
\hline 07002 & 0533 & 32 & $\begin{array}{l}3000850,3050850,3100850,2950845,3000845,3050845, \\
3100845,2800840,2850840,2900840,2950840,3000840, \\
3050840,2800835,2850835,2900835,2950835,3000835, \\
2750830,2800830,2850830,2900830,2700825,2750825, \\
2800825,2700820,2750820,2650815,2700815,2750815 \\
2650810,2700810\end{array}$ \\
\hline 14001 & 0729 & 12 & $\begin{array}{l}3300720,3350720,3250715,3300715,3350715,3400715, \\
3450715,3200710,3250710,3300710,3350710,3400710\end{array}$ \\
\hline 21023 & 0847 & 5 & $3800650,3850650,3750645,3800645,3850645$ \\
\hline 34003 & 1438 & 7 & $\begin{array}{l}\text { 6150340, 6200340, 6100335, 6150335, 6200335, 6100330, } \\
6150330,\end{array}$ \\
\hline 38003 & 1589 & 7 & $\begin{array}{l}5150230,5150225,5200225,5200220,5250220,5300220, \\
5300215\end{array}$ \\
\hline 43005 & 1623 & 14 & $\begin{array}{l}\text { 4050165, 4100165, 4150165, 4200165, 4250165, 4100160, } \\
\text { 4150160, 4200160, 4100155, 4150155, 4200155, 4150150, } \\
\text { 4200150, 4200145 }\end{array}$ \\
\hline 47007 & 4 & 6 & $2600065,2650065,2600060,2650060,2600055,2650055$ \\
\hline 54008 & & 40 & $\begin{array}{l}3400300,3400295,3450295,3500295,3550295,3600295, \\
3300290,3350290,3400290,3450290,3500290,3550290, \\
3600290,3200285,3250285,3300285,3350285,3400285, \\
3450285,3500285,3550285,3600285,3200280,3250280, \\
3300280,3350280,3400280,3450280,3500280,3550280, \\
3600280,3300275,3350275,3400275,3450275,3500275, \\
3550275,3600275,3550270,3600270\end{array}$ \\
\hline
\end{tabular}




\section{Figures}

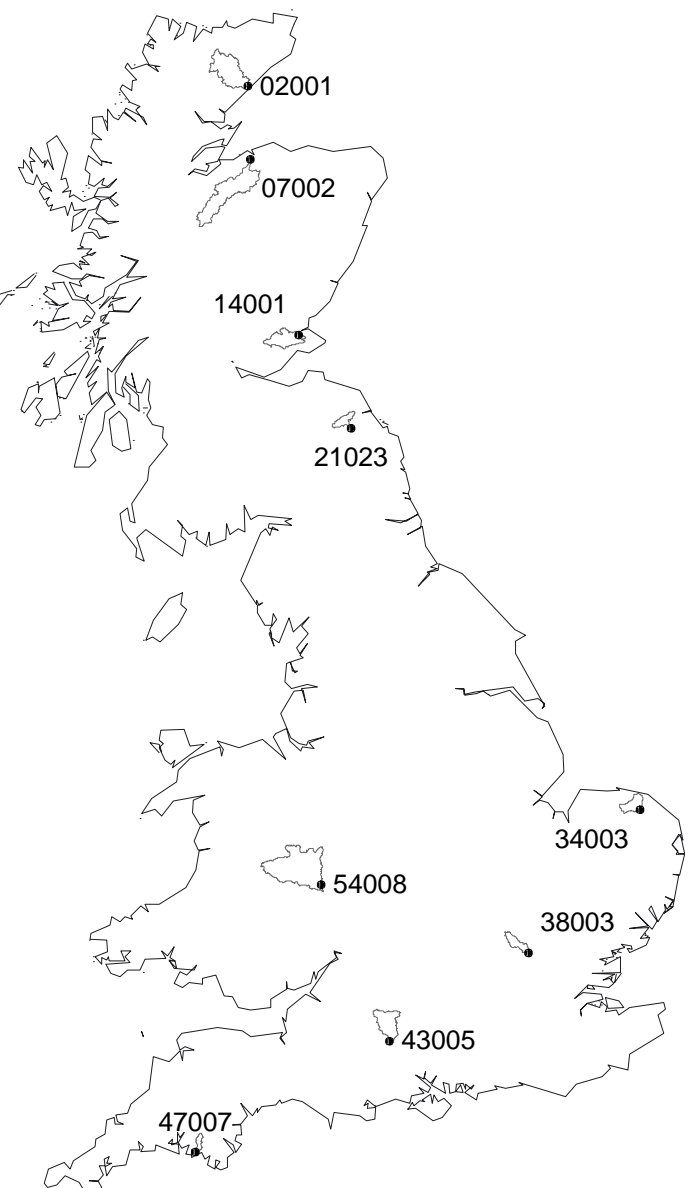

Figure 1 Boundaries and outlet locations of the nine catchments. 

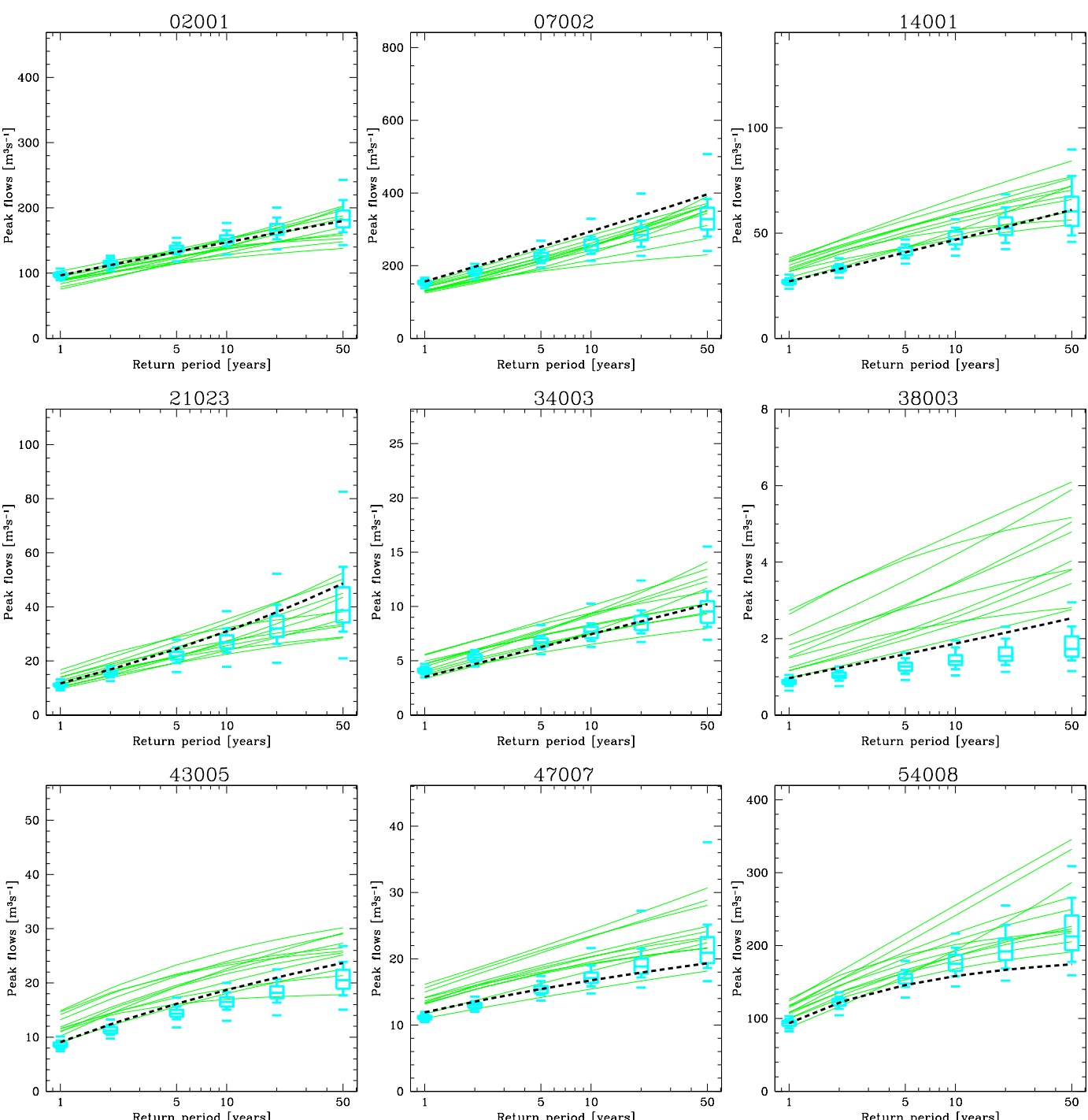

Figure 2 Flood frequency plots showing the three sets of baselines: simulated with observed data (one, black dashed); simulated with RCM baseline data (11, green solid); simulated using weather generator baseline data $(100$, shown by cyan boxes-andwhiskers). The box delineates the 25th-75th percentile range and the whiskers the 10th90th percentile range, with the median (50th percentile) shown by the line dividing the box. Additional markers outside the whiskers indicate the minima and maxima. 
Precipitation
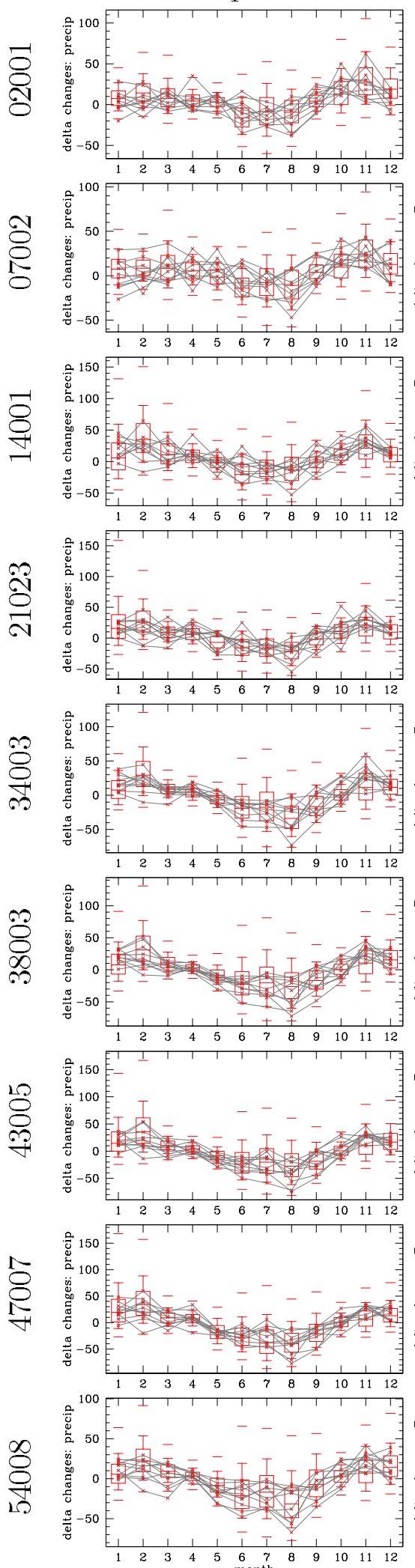

Temperature

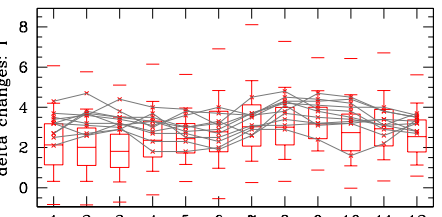

PE
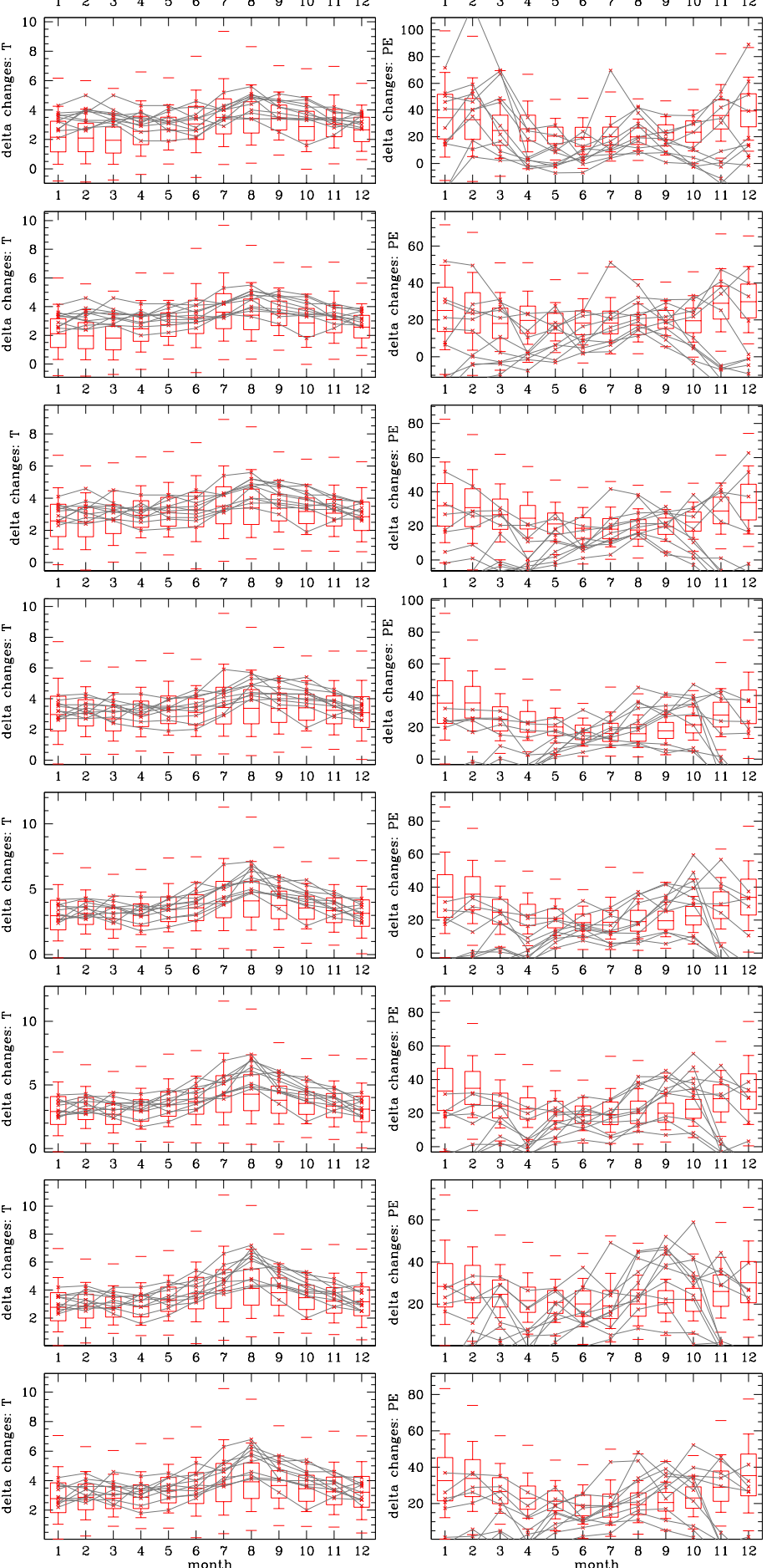

Figure 3 The monthly Sampled Data change factors (boxes-and-whiskers) and RCMderived change factors (crosses) for each catchment, for precipitation, temperature and PE. The box-and-whisker plots delineate the same percentiles as in Figure 2. The RCM monthly change factors are connected (grey lines) for each member of the RCM ensemble. 
a) histograms

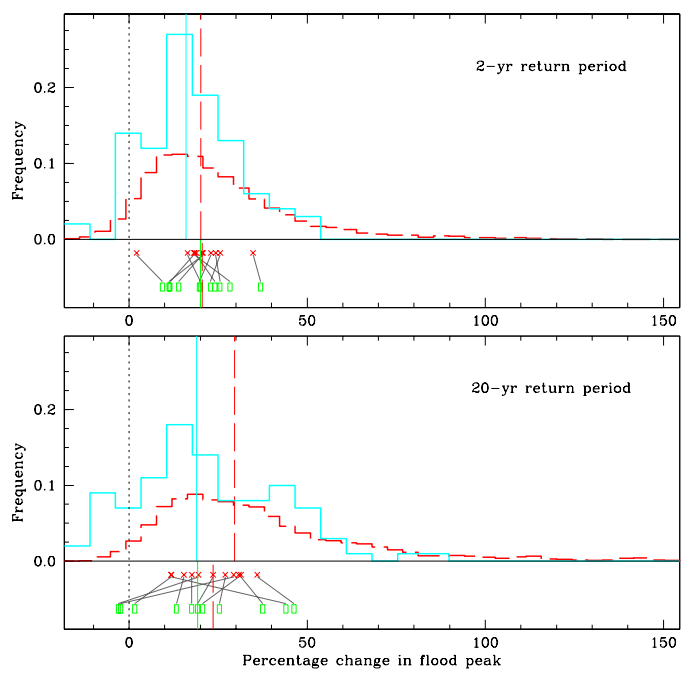

b) cdfs

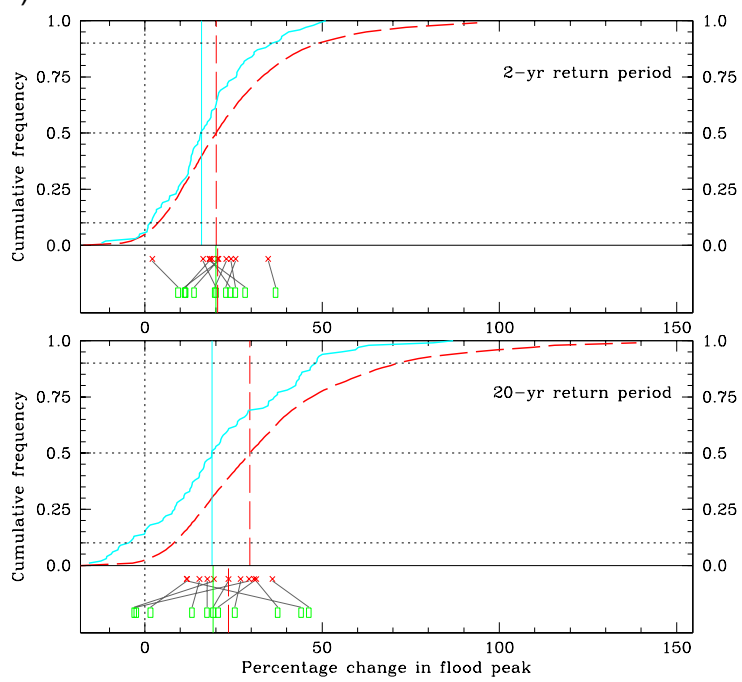

Figure 4 The percentage change in flood peaks at the 2- and 20-year return periods for catchment 47007, plotted as a) histograms and b) cdfs for Method 1 (10,000 SD-CF - red dashed line) and Method 2 (100 WG-TS - cyan solid line). Also plotted, below the zero xaxis, are the results for Method 3a (11 RCM-CF - red crosses) and Method 3b (11 RCM-TS - green rectangles), joined for the corresponding members of the 11-member RCM ensemble (grey lines). The median results for each method are shown by corresponding vertical lines (above the zero $\mathrm{x}$-axis for Methods 1 and 2; below the zero $\mathrm{x}$-axis for Methods 3a and 3b; dashed for Methods 1 and 3a; solid for Methods 2 and $3 b$ ). The $10^{\text {th }}$ and $90^{\text {th }}$ percentiles of the cdfs can be obtained from b) by noting where the $10^{\text {th }} / 90^{\text {th }}$ percentile lines (dotted) intersect the cdfs. 
a) 2-year return period

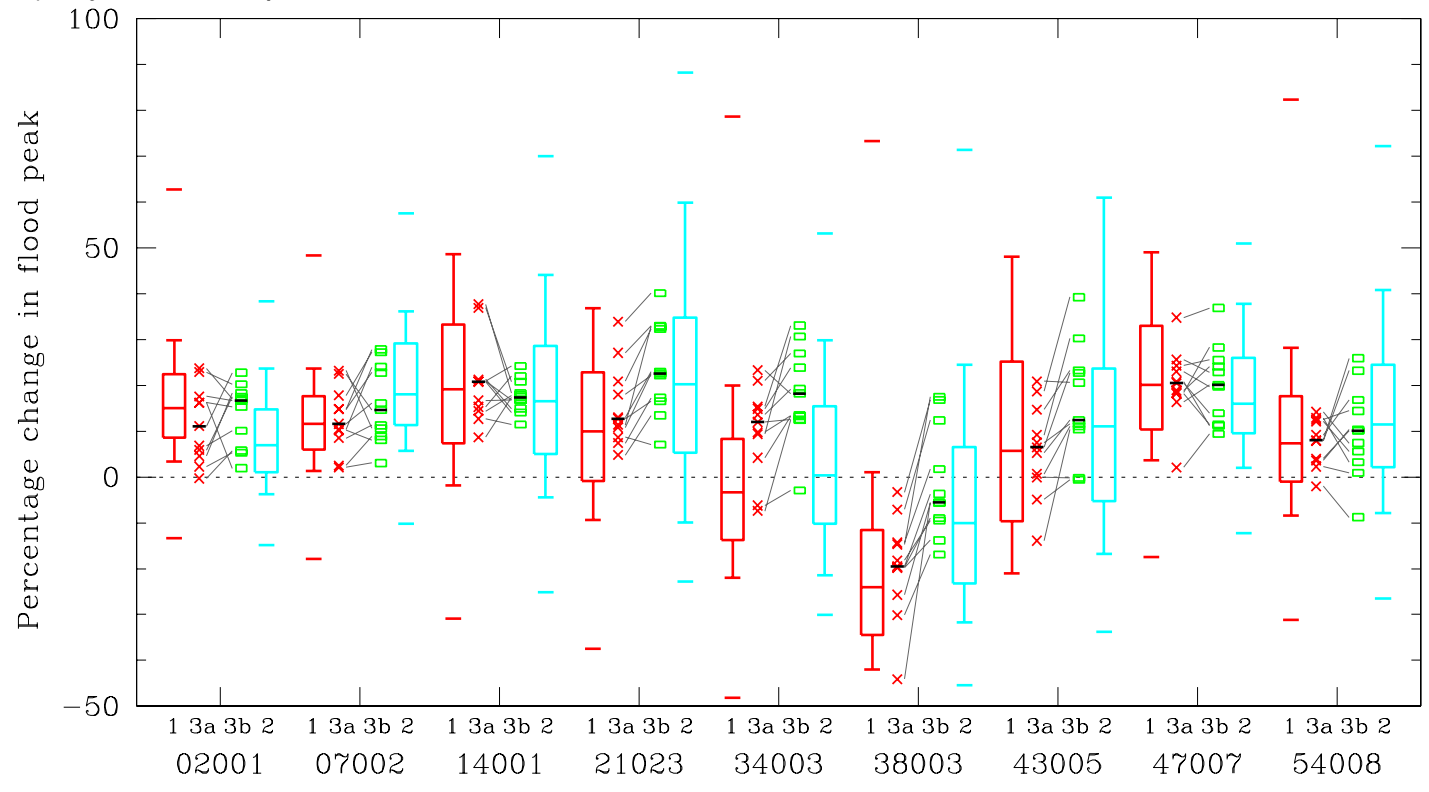

b) 20-year return period

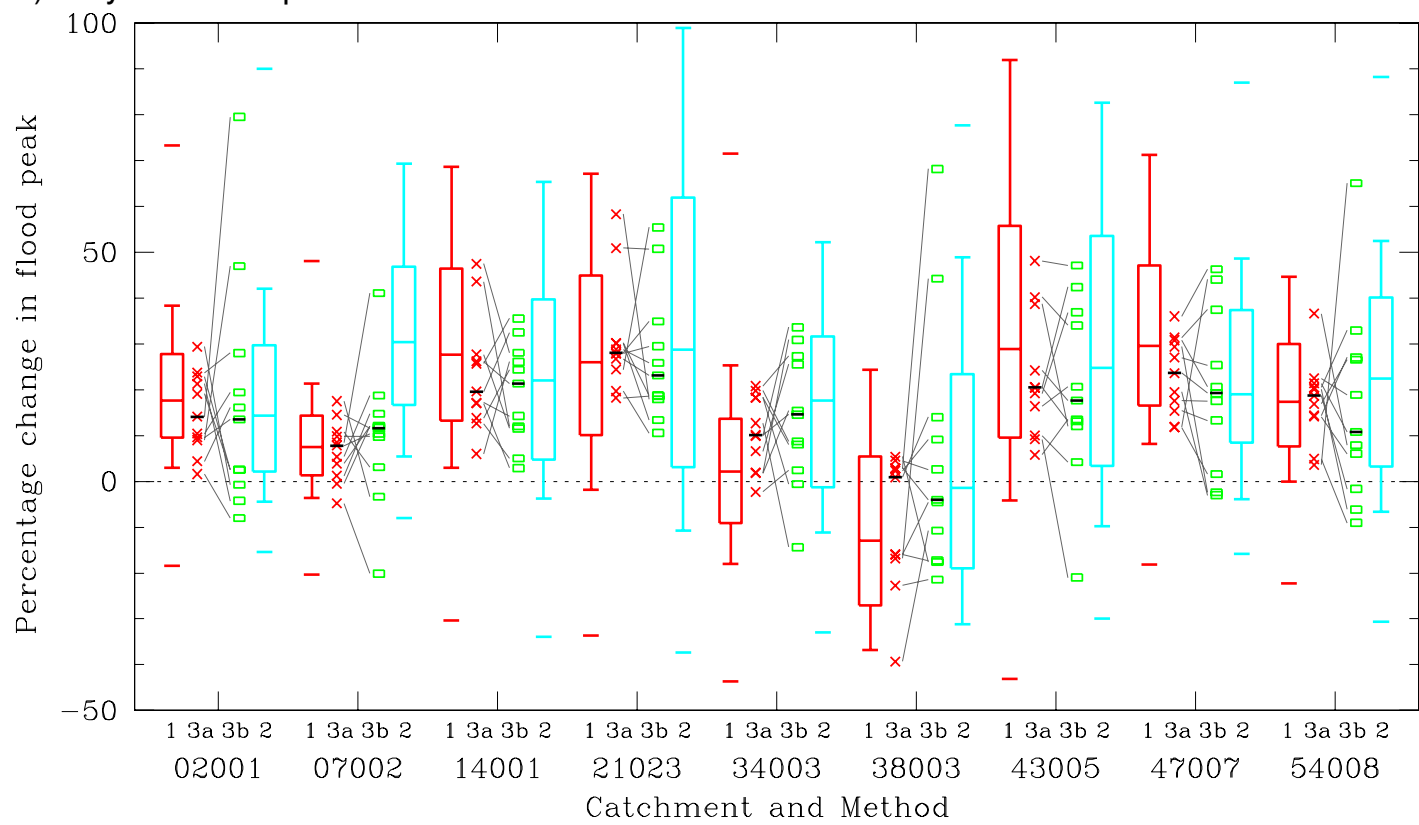

Figure 5 Summary of the results for the nine catchments at the a) 2-year and b) 20-year return period. Box-and-whisker plots are used for Methods 1 (SD-CF - red) and 2 (WG-TS - cyan), with 11 individual points plotted for Methods 3a (RCM-CF - red crosses) and 3b (RCM-TS - green rectangles). The box delineates the $25^{\text {th }}-75^{\text {th }}$ percentile range and the whiskers the $10^{\text {th }}-90^{\text {th }}$ percentile range, with the median $\left(50^{\text {th }}\right.$ percentile $)$ shown by the line dividing the box. Additional markers outside the whiskers indicate the minima and maxima, if within the plotted range of -50 to +100 . The points for Methods $3 a$ and $3 b$ are joined for the corresponding members of the RCM ensemble (grey lines), and the medians for these methods are shown by black horizontal bars. 


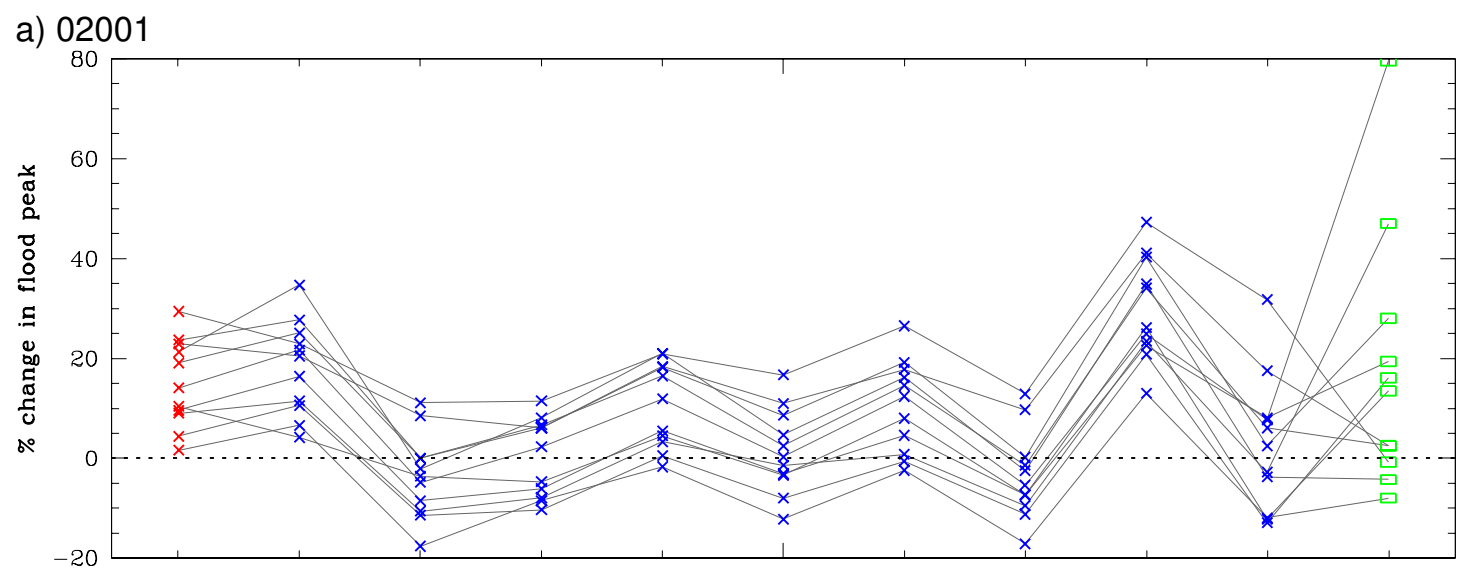

b) 43005

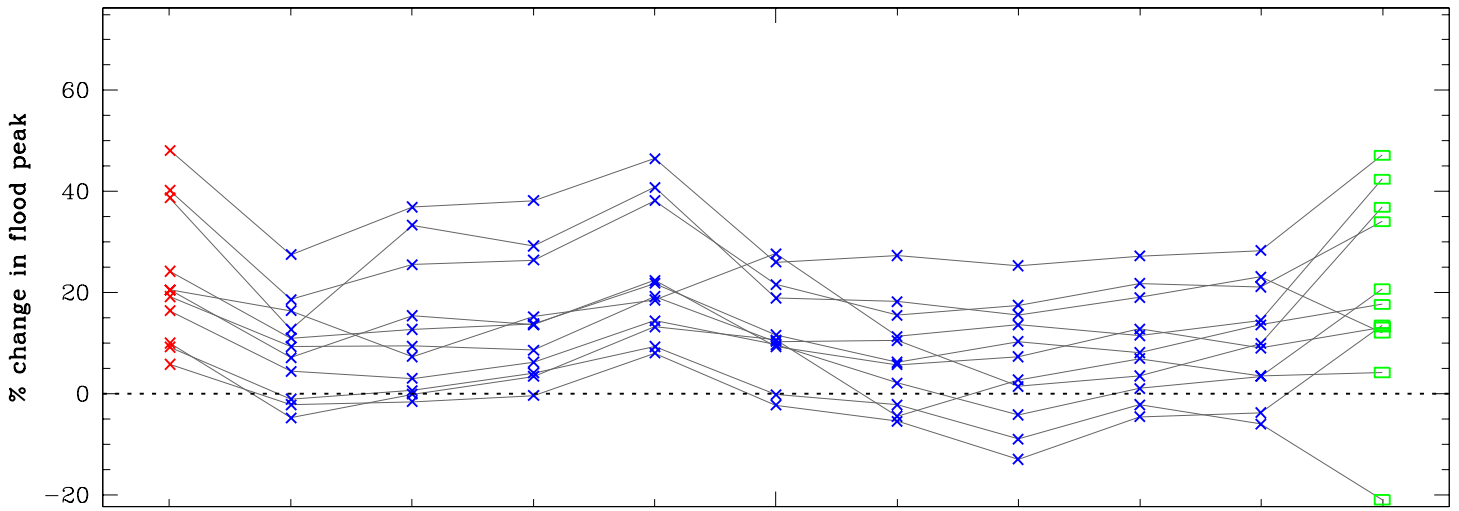

c) 47007

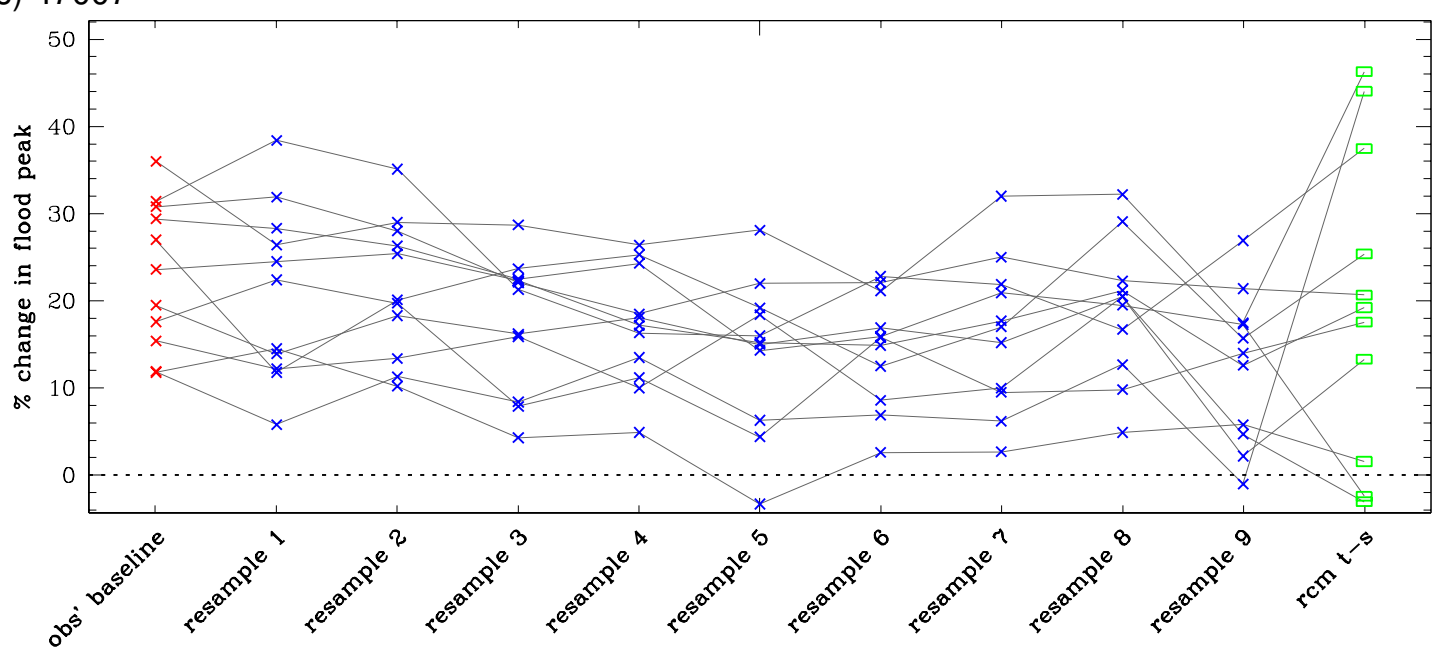

Figure 6 Changes in flood frequency at the 20-year return period, for catchments 02001 , 43005 and 47007 . The results from Method 3a (RCM-CF with the observed baseline; red crosses on the left) and Method $3 \mathrm{~b}$ (RCM-TS; green rectangles on the right) are compared to those from applying the RCM-derived change factors to alternative baselines (derived from resampling the observed baseline in 1-month blocks; blue crosses). The points are joined, in each case, to those derived using the same RCM ensemble member (lines). 